\title{
Clinical Aspects and Relevance of Molecular Diagnosis in Late Mucocutaneous Leishmaniasis Patients in Paraná, Brazil
}

Andréa Thomaz-Soccol ${ }^{1}$, Marcos Mocellin $^{2}$, Fabiane Mulinari ${ }^{3}$, Edilene Alcântara de Castro $^{4}$, Flávio de Queiroz-Telles ${ }^{5}$, Fernanda de Souza Alcântara ${ }^{4}$, Marcello Tortelli Bavaresco $^{5}$, Luciane Hennig ${ }^{5}$, Anielo Andraus ${ }^{5}$, Ennio Luz ${ }^{5}$ and Vanete Thomaz-Soccol ${ }^{4,6 *}$ ${ }^{1}$ Otorrinolaringologista, Médica; ${ }^{2}$ Serviço de Otorrinolaringologia; Hospital das Clínicas; Universidade Federal do Paraná. ${ }^{3}$ Departamento de Clínica Médica, Dermatologia; Hospital de Clínicas; Universidade Federal do Paraná. ${ }^{4}$ Laboratório de Parasitologia Molecular; Departamento de Patologia Básica; Universidade Federal do Paraná. ${ }^{5}$ Departamento de Saúde Comunitária; Setor de Ciências da Saúde, Universidade Federal do Paraná. ${ }^{6}$ Biotecnologia Industrial; Universidade Positivo; Curitiba - PR - Brasil

\begin{abstract}
The aim of the present work was to study the clinical aspects and relevance of molecular diagnosis in late mucocutaneous leishmaniasis patients in Parana, Brazil. Twenty one suspected cases of mucocutaneous leishmaniasis (MCL) in patients from the endemic areas of leishmaniasis were assessed. Different methods used in diagnosing the disease and the polymerase chain reaction (PCR) technique were compared in order to establish the sensitivity of each method. Out of the 21 patients analyzed, $14.3 \%$ presented other etiologies such as vasculitis, syphilis, and paracoccidioidomycosis, with all tests negative for leishmaniasis. Out of the remaining 15 patients, $6.7 \%$ cases were confirmed for leishmaniasis by direct examination; $46.67 \%$ were positive for culture, which allowed isolating and identifying the parasite and - with the PCR technique - it was possible to diagnose 100\% MCL patients for all the three repetitions of exams. The PCR optimized for the present work proved to be an auxiliary method for diagnosing leishmaniasis applicable in the patients carrying MCL due to Leishmania (Viannia) braziliensis and did not need culture to be performed, resulting in a faster diagnosis.
\end{abstract}

Key words: Mucocutaneous leishmaniasis, molecular diagnosis, Leishmania (Viannia) braziliensis

\section{INTRODUCTION}

Leishmanisis is a zoonosis caused by a protozoa belonging to the genus Leishmania Ross, 1903. In humans, there are three clinical forms: tegumentary (ATL), mucocutaneous (MCL), and visceral leishmaniasis (VL). By its etiology, the tegumentary form can have twelve species, whereas the visceral form is caused by two species
(Dedet, 2009). In the New World, the cutaneous forms are present from the south of Mexico to the north of Argentina and south of Brazil, especially the MCL form caused by L. braziliensis (Opas, 1994; Who, 2006; Brasil, 2007).

In the south region of Brazil, tegumentary leishmaniasis has increased its incidence since 1980's (Brasil, 2007). In the State of Parana the epidemiological outbreaks happened in 1994 and

*Author for correspondence: vsoccol@up.com.br 
2002 with 1400 and 988 new cases, respectively, registered by the Health Department of the State, and between 2000 and 2004, 3900 cases of leishmaniasis were reported in humans (Sesa, 2002; Brasil, 2007). Autochthonous foci are found in the Ribeira river valley, where the illness has been reported for more than a century ( $>11$ human cases/year) (Castro et al., 2005). In the north and northwest regions of the State, cases have been reported since the 1940's (when the region was colonized) and have been increasing in number (Castro et al., 2002; Curti et al., 2009). In the central region, leishmaniasis has been reported since 2003 (Thomaz-Soccol et al., 2009). The protozoan, isolated both in humans and animals, was identified by isoenzymes and RAPD-PCR as L. (V.) braziliensis and was the only autochthonous species (Silveira et al., 1999; Thomaz Soccol et al., 2003; Castro et al., 2005; Pereira et al., 2008, Thomaz Soccol et al., 2009). Several phlebotomine species are present in the State of Parana, and the dominant and vector species found infected is Lutzomyia whitmani (Luz et al., 2000; Teodoro et al., 2004).

Leishmania (V.) braziliensis causes the most severe form of the disease and may affect mucous membranes, either in its secondary or tertiary form. The primary phase does not differ from other tegumentary forms and may progress to spontaneous healing. However, the parasite remains dormant, in variable durations: there are reports of it lasting up to 40 years or the whole life of an individual (Dedet, 2009). Its secondary form affects the mucous membranes of the nose, lips, and eye-lids contiguously when the primary cutaneous lesion is close-by. The tertiary form, termed as 'late mucous leishmaniasis', occurs generally between five and twenty years after the primary lesion. It affects the nasobucopharingeal and laryngeal areas damaging mainly mucous membranes and cartilages, bringing about severe sequels for the patient, such as weight loss and malnutrition, which may even lead to death. An early diagnosis of the disease is fundamental to avoid the complications and severe sequels. However, the classical diagnostic methods are very difficult presenting low sensitivity. Between 2005 and 2007, many MCL were detected at various medical services of the University Hospital of the UFPR and to confirm the correct diagnostic we carried out the present work aiming at assessing the extent of detection of Leishmania in mucosal lesions.

\section{MATERIAL AND METHODS}

Twenty-one patients - 11 men and 10 women ranging from 34 to 77 years of age - were submitted to the leishmaniasis diagnosis because they presented granulomatous lesions in mucous membranes. The patients were received at different medical service centers of the University Hospital of the Federal University of Parana (Otorhinolaryngology, Dermatology, and Infectious Disease Services) and at the laboratory of Molecular Parasitology. The inclusion criteria for diagnosing leishmaniasis were the following: patients with nasal and/or palate granulomatous reaction living or having lived for more than 20 years in the ATL endemic zone. We excluded patients with intercurrent bacterial or fungal superinfection of the ulcer.

The differential diagnosis of the mucosal form included paracoccidioidomycosis, leprosy (lepromatous), histoplasmosis, tertiary syphilis, sarcoidosis, Wegener's granulomatosis, T-cell angiocentric lymphoma, rhinoscleroma and basal cell carcinoma, tuberculosis, and HIV. The tests performed for the tuberculosis were tuberculin test for TB (PPD skin test), complement fixation test for syphilis, and enzyme-linked immunosorbent assay for acquired immunodeficiency syndrome (HIV).

For the paracoccidioidomycosis diagnosis, cultivation in a specific medium was done. In order to exclude the carcinomas, histopathological biopsies were made. Leishmaniasis diagnostic was performed by imprint, culture, and polymerase chain reaction - PCR (Castro et al., 2005; Pereira et al., 2008). For the imprint technique, lesion scraping was performed, spread on a slide, fixed in methanol, and stained with MayGrünwaldGiemsa. To isolate the parasite, biopsies or aspirations were performed. The fragments obtained were put in $0.5 \mathrm{ml}$ of sterile phosphatebuffered saline with $1,000 \mathrm{U} / \mathrm{ml}$ penicillin and 0.3 $\mathrm{mg} / \mathrm{ml}$ streptomycin. The biopsy was divided (to culture and PCR) evenly in a biosafety cabinet under sterile conditions. The first fragment were macerated and inoculated in culture medium (Novy-MacNeal-Nicolle-NNN) and transferred every seven days to new tubes containing fresh medium. The cultures were labeled with the patient's unique identifier and the date of collection, incubated vertically at 22 to $24^{\circ} \mathrm{C}$ under standard atmospheric conditions, and independently examined by two different 
investigators every 6 to 7 days under an inverted microscope at 400X magnification. The cultures were incubated and examined for 30 days before being considered negative.

The isolated parasites were cryopreserved in the Leishmania strain bank of the Molecular Parasitology Laboratory of the UFPR (LPM/UFPR), where they were catalogued under the abbreviation CUR (as in Curitiba), followed by the number corresponding to their order of arrival (Table1). The second fragment was used to extract the DNA, maceration in mortar was performed, followed by five cycles of freezing and defrosting. The DNA was extracted using the ChargeSwitch ${ }^{\circledR}$ gDNA Mini Tissue kit. The DNA was stored at $80^{\circ} \mathrm{C}$ until use.

The PCR was carried out as proposed by Pereira et al. (2008). Two primers were used: MP1L/MP3H (5'tactccecgacatgcctctg3') 5'gaacggggtttctgtatg3'), amplifying 70bp fragments and B1/B2 (5'ggggttggtgtaatatagtgg $3^{\prime} /$ 5'ctaattgtgcacggggagg3'), amplifying $750 \mathrm{bp}$ fragments or bands. For amplification, the reagent concentrations were $10 \mathrm{mM}$ of Tris- $\mathrm{HCl}$ buffer (pH 8.3), $50 \mathrm{mM}$ of $\mathrm{KCl}, 1.5 \mathrm{mM}$ of $\mathrm{MgCl}_{2}$, $0.01 \%$ gelatin (MERCK), $200 \mu \mathrm{M}$ of dNTP, 25 pmoles of each primer, and $0.5 \mathrm{U}$ of Taq platinum; 2,4 , and $8 \mu \mathrm{L}$ of DNA extracted from patients' tissues containing parasites; and ultra-pure water to make $25 \mu \mathrm{L}$ of reaction volume. The amplification was carried out at $94^{\circ} \mathrm{C}$ initial denaturation for $2 \mathrm{~min}$, followed by 29 cycles of $94^{\circ} \mathrm{C}$ denaturation for $1 \mathrm{~min}, 54^{\circ} \mathrm{C}$ annealing for $1 \mathrm{~min}, 72^{\circ} \mathrm{C}$ extension for $1 \mathrm{~min}$, and $72^{\circ} \mathrm{C}$ final extension for $10 \mathrm{~min}$.

After amplification, the products were examined by electrophoresis in agarose gel (1.6\%) and stained for $20 \mathrm{~min}$ in ethidium bromide, viewed under ultraviolet light and photographed.

The DNA of reference strains of Leishmania braziliensis, L. infantum, and L. amazonensis were extracted and used as positive controls. The negative control consisted of $20 \mu \mathrm{L}$ of the mixture and $5 \mu \mathrm{L}$ of ultrapure water replacing the DNA, for controlling the environmental contamination. The work was carried out with the approval of the Ethics Committee of the University Hospital of the Federal University of Paraná - Brazil.

The patients had been informed about the purpose of the study and they signed a consent term.

\section{RESULTS}

\section{Clinical examination}

All the patients had complains about nasal obstruction, nasal crust formation, serosanguineous rhinorrhea, and epistaxis. The aesthetic complaints included dropping of the nasal tip, saddle-like nose, and enlarged pyramid (Figure 1). Frontal rhinoscopy showed nasal mucosa with chronic granulomatous response in $72.4 \%$ cases. There was presence of crusts in the nasal cavities in $86.7 \%$ cases. Septum cartilage was intact in $17.64 \%$ and perforation was found in $35.29 \%$ cases. The granulomatous lesions were located mainly in the frontal region of the quadrangular cartilage and caudal septum. However, lesions were also seen in the inferior and medium turbinate bones and lateral wall of the nose.

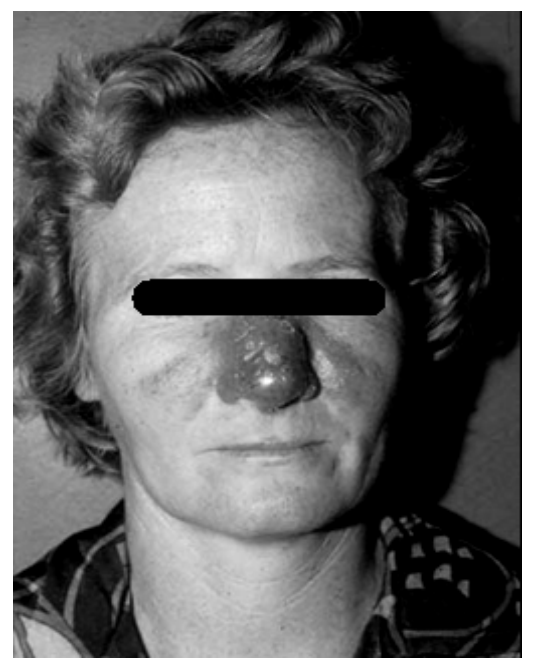

Figure 1 - Extensive nasal lesion in patient included in the present study 


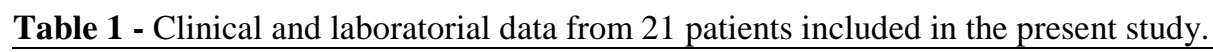

\begin{tabular}{|c|c|c|c|c|c|c|c|c|}
\hline \multicolumn{9}{|c|}{ Test Results } \\
\hline Patient & Sex & Age (years) & Origin in the State & Clinical form & Imprint & Culture & PCR & Final Diagnosis \\
\hline 1 & Female & $*$ & North & Mucous & $\mathrm{Neg}$ & Pos & Pos & ML \\
\hline 2 & Female & $*$ & West & Mucous & Neg & Neg & Neg & Treated \\
\hline 3 & Female & 46 & Central & Mucous & Neg & Neg & Neg & Treated \\
\hline 4 & Female & 62 & $*$ & Mucous & $\mathrm{Neg}$ & Neg & $\mathrm{Neg}$ & Treated \\
\hline 5 & Male & 57 & North & Mucous & $\mathrm{Neg}$ & Pos & Pos & $\mathrm{ML}+\mathrm{HIV}$ \\
\hline 6 & Male & $*$ & $*$ & Mucous & Pos & Pos & Pos & ML \\
\hline 7 & Male & 70 & $*$ & Mucous & Neg & Neg & Pos & $\mathrm{ML}+\mathrm{HIV}$ \\
\hline 8 & Male & 46 & $*$ & Mucous & $\mathrm{Neg}$ & $\mathrm{Neg}$ & Pos & ML \\
\hline 9 & Male & 47 & North & Mucous & $\mathrm{Neg}$ & Pos & Pos & ML \\
\hline 10 & Male & 34 & $*$ & Mucous & $\mathrm{Neg}$ & $\mathrm{Neg}$ & Pos & ML \\
\hline 11 & Male & 44 & North & Mucous & $\mathrm{Neg}$ & Pos & Pos & ML \\
\hline 12 & Male & 57 & $\mathrm{SC}$ & Mucous & $\mathrm{Neg}$ & $\mathrm{Neg}$ & Neg & Vasculitis \\
\hline 13 & Male & 49 & $*$ & Mucous & $\mathrm{Neg}$ & Pos & Pos & ML \\
\hline 14 & Male & 73 & North & Mucous & Neg & Neg & Pos & ML \\
\hline 15 & Female & 48 & $*$ & Mucous & $\mathrm{Neg}$ & $\mathrm{Neg}$ & Pos & ML \\
\hline 16 & Female & 77 & East & Mucous & $\mathrm{Neg}$ & Neg & Neg & Syphilis \\
\hline 17 & Female & $*$ & North & $\begin{array}{l}\text { Disseminated } \\
\text { Cutaneous }\end{array}$ & Neg & Neg & $\mathrm{Neg}$ & $\mathrm{HIV}+\mathrm{Tb}$ \\
\hline 18 & Female & 45 & Northwest & Mucous & Neg & $\mathrm{Neg}$ & Pos & ML \\
\hline 19 & Female & $*$ & $*$ & Mucous & $\mathrm{Neg}$ & $\mathrm{Neg}$ & Pos & ML \\
\hline 20 & Male & 61 & $*$ & Mucous & $\mathrm{Neg}$ & $\mathrm{Neg}$ & Pos & ML \\
\hline 21 & Female & 77 & East & Mucous & $\mathrm{Neg}$ & Pos & Pos & ML \\
\hline
\end{tabular}

$\mathrm{ML}=$ Mucous leishmaniasis; $\mathrm{HIV}=$ Carrier of human acquired immunodeficiency virus; $\mathrm{Tb}=$ positive for tuberculosis; $\mathrm{PCR}=$ polimerase chain reaction; $*=$ unknown

Laryngologic manifestations were observed in $11.76 \%$ of the patients that presented dysphonia, edema of the ventricular bands, and vegetating tumor on the vocal folds. The concomitant mucocutaneous lesions were observed in $18.18 \%$ cases (Table 2).

Table 2 - Clinical aspects observed in mucocutaneous leishmaniasis patients.

\begin{tabular}{lc}
\hline Place of lesions & \% \\
\hline Nose (with septum perforation) & 35.29 \\
Nose (without septum perforation) & 17.64 \\
Larynx & 11.76 \\
Palate and nose & 35.29 \\
Concomitant cutaneous lesion & 18.18 \\
\hline
\end{tabular}

\section{Lab tests}

Studying the amastigotes, the slide test was positive for only one patient and it was possible to isolate the parasite in culture from seven patients. Fifteen patients presented positive results for leishmaniasis in the PCR tests for both pairs of primers used (Figures 2 and 3).

Two patients presented palatal lesions in the soft palate with naso-oral fistulae, and $35.29 \%$ presented concomitant naso-oral lesions.

In the PCR test, the comparison of the amplified fragments with reference strains of different species of Leishmania confirmed that the etiological agent was L. (Viannia) braziliensis (Figure 3).

Among the 15 patients diagnosed with leishmaniasis, two had HIV and ML concomitantly. Out of the six patients presenting negative result in the PCR test, three (14.3\%) presented positive tests for HIV and TB, syphilis and vasculitis, and another three (14.3\%) had already been being treated for leishmaniasis for 20 days.

The comparison between the culture and PCR tests showed that the sensitivity for culture was $46.67 \%$ and $100 \%$ for PCR (Table 3 ). 


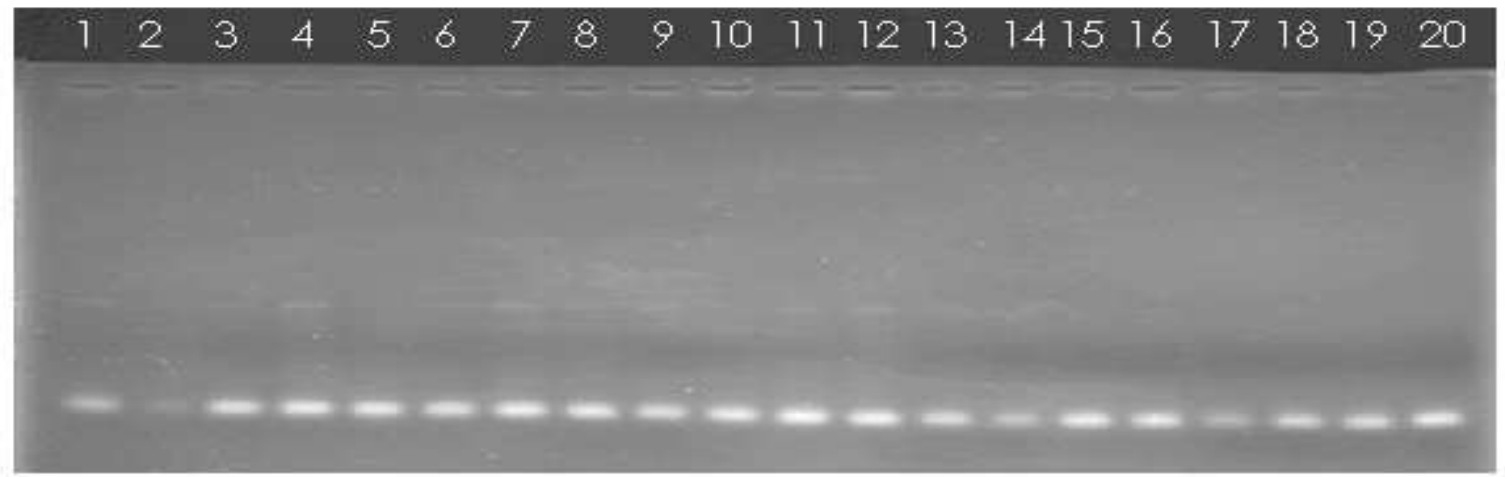

Figure 2 - Diagnosis by PCR using primers MP1L/MP3H for Leishmania (Viannia) braziliensis with a 70pb amplification product. Column 1 - Leishmania (V.) braziliensis reference strain. Columns 2 to 6: PCR from parasites isolated in culture of patients with mucosal leishmanisis. Columns 7-20: amplification of the 70pb product in biopsies from 15 patients with ML.

\section{Primer B1/B2}

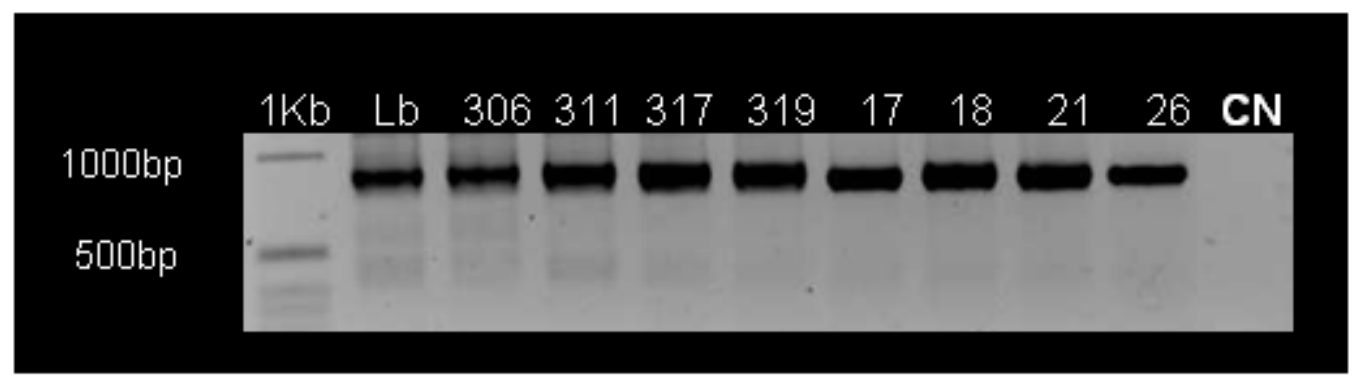

Figure 3 - Diagnosis by the PCR technique using primers B1/B2 for the complex Leishmania braziliensis with a 750bp amplification product. Column 1: molecular weight marker of 100bp. Column 2: Lb = Leishmania (Viannia) braziliensis reference strain. Columns 3 to 10: patients with mucosal lesions. Column 11: negative control.

Table 3 - Sensitivity for culture and PCR approaches.

\begin{tabular}{lccc}
\hline Culture & Positive PCR & Negative PCR & Total \\
\cline { 2 - 4 } Positive & 7 & 0 & 7 \\
Negative & 8 & 6 & 14 \\
\hline TOTAL & 15 & 6 & 21 \\
\hline
\end{tabular}

\section{DISCUSSION}

Many studies have demonstrated the importance of PCR as diagnosis in the patients carrying cutaneous and visceral leishmaniasis (Brujin et al., 1992, Guevara et al., 1992, Arevalo et al., 1993, Eresh et al., 1994, Mimori et al., 1998, Piñero et al., 1999, Lachaud et al., 2002, Pereira et al., 2008). It has been proved to be particularly useful in diagnosing the infections by Leishmania belonging to the subgenus Viannia, as the number of parasites in the lesions is usually scarce (Brujin et al., 1993; Lopes et al., 1993; Aviles et al., 1999; Pirmez et al., 1999). However, few authors (Piñero et al., 1999) have assessed its use in late mucosal leishmaniasis. Several PCR protocols have been developed for detecting the Leishmania species using either purified DNA of parasite cultures or clinical specimens such as lesion biopsies from scar spots or blood (Brujin et al., 1993; Lopes et 
al., 1993; Avilez et al., 1999; Pirmez et al., 1999; Lachaud et al., 2002). Based on those data, the present work made an attempt to optimize the PCR conditions for detecting the Leishmania species as a diagnostic technique for Mucocutaneous leishmaniasis. The primer MP1L and MP3H are directed to the kDNA minicircle increasing the probability of detecting the DNA of the parasite (Lopes et al., 1993). It was observed that the proposed primers presented good specificity for detecting $L$. braziliensis in the samples analyzed. However, as the amplified fragment had only $70 \mathrm{bp}$, it could be easily mistaken for the debris or a primer dimer. Hence, an attempt was made to assess another primer pair which presented a larger fragment. The B1/B2 primer was described as specific for the L. braziliensis Complex and, under adequate conditions, the reaction would be able to detect less than a phentogram of kDNA without the need for hybridization with a kDNA probe (Brujin et al., 1993). Such efficiency is explained by the fact a single parasite contains about 10,000 minicircles of 700-800 base pairs each, and the detection limit of the technique corresponds to one tenth of a parasite. The PCR product observed was approximately $750 \mathrm{pb}$ and, according to Brujin et al. (1993), it was the diagnostic for the $L$. braziliensis complex. Therefore, the B1/B2 primer pair proved to be highly specific. After standardizing the technique, the primer pair was used as biopsy material and was compared to the reference strains of $L$. braziliensis and others Leishmania species. The B1/B2 primer pair has been tested with material straight from biopsies of leishmaniasis patients from South America, potential reservoirs (wild animals), and vectors. The tests indicated that those primers were adequate for diagnosing leishmaniasis and potentially useful in an epidemiological assessment.

In our work from 15 patients with diagnostic confirmed by two or more techniques, the parasite was isolated in 7/15 in culture method; and, by PCR, DNA bands were observed in $15 / 15$. The PCR sensitivity for diagnosing ATL (cutaneous form) varied from 81.5 to $100 \%$ (Medeiros et al., 2002; Lopez et al., 1993; Brujin et al., 1993; Rodriguez et al., 1994; Belli et al., 1998 and Pereira et al., 2008). In a more recent work analyzing 52 patients with cutaneous leishmaniasis, Gomes et al. (2008) detected 96\% positive cases through PCR and 69\% through the parasitological tests.
In order to avoid false positives each step was performed in separate rooms, and negative control was included.

PCR was negative in six patients and one could think they were false negatives. However, as three patients were already undergoing treatment and another three had their diagnoses confirmed for other pathologies, this hypothesis was ruled out.

It has been reported that the diagnosis of late mucosal leishmaniasis is difficult by any methodand the parasite demonstration is the first choice procedure (Who, 2006; Boaventura et al., 2009; Dedet, 2009). But the detection of the parasite is inversely proportional to time of evolution of the lesion (note that the mucosal lesion usually occurs after two years) and that secondary contamination contributes to decreasing the sensitivity of the method. The isolation of the parasite in culture is usually time-consuming and, if good antisepsis is not done, contaminations may occur mainly by fungi. The anatomopathological test for diagnosing leishmaniasis has a sensitivity level between 20 to $40 \%$ and, in most cases, only an infection suggesting lesion is observed rather than the presence of the parasite (Mayrink et al., 1979). The diagnostic techniques have been constantly improved to ensure the desired effectiveness. Concomitantly, new methods have also been developed aiming at identifying the species as fast and as precisely as possible. Molecular techniques appear promising to offer an effective diagnosis that may have low cost (Mimori et al., 1998; Pereira et al., 2008; Gomes et al., 2008) and, as medication for ATL is highly toxic, it is fundamental for the medical practitioners to have more accurate methods at their disposal. According to data from the Ministry of Health, 13,316 cases of ATL were registered in Parana between 1980 and 2005, with a significant increase in the number of cases in 1986, 1994, and 2002 (Brasil, 2007). Between the 1980's and early 1990's many cases may not have been diagnosed and, therefore, not treated, which could support the current increase in ML cases.

Many patient reports presented a lesion which was difficult to heal, or left an endemic zone 15-10 years before. Another hypothesis for the increasing number of ML cases would be the long-lasting course of the treatment and the severe side effects, which could results the discontinuation of the treatment. A third hypothesis could be the low dose of antimoniate used to treat the cutaneous form caused by $L$. (V.) braziliensis, that would not 
be enough to prevent the evolution of the late mucosal form.

It has been demonstrated that the treatment used did not actually prevent the occurrence of mucosal lesions. Cure rates of mucosal lesions can be from $51 \%$ - in case of sodium stibogluconate - to $88 \%$, with meglumine antimoniate (Amato et al., 2008). In the State of Parana - where L. braziliensis is authochtone - because there has been an increase in the number of cases of mucous lesions, the treatment of primary cutaneous lesions could be changed to prevent the spread of the parasite in the facial mucosa.

Seventeen patients reported the presence of a primary cutaneous scar and they had already been treated before for leishmaniasis at some other dermatological and/or infectious disease centers. The number of ampoules of glucantime received by the patient varied from 20 to 120 . The time of appearance between the primary and the mucosal lesions varied from 2 to 20 years.

The present works intended to alert the otolaryngologists on the increasing number of patients presenting granulomatous lesions in the palate, in the nasal septum, and edema on false and true vocal folds, and also for including the mucosal leishmaniasis in the list of etiologies for further studies because late diagnosis leads to necrosis and disfiguring facial mutilations causing severe psychosocial consequences, such as the exclusion of the individual from family life.

\section{ACKNOWLEDGEMENTS}

The authors express their thanks to the SETI UGF - Paraná Tecnologia, to the Secretaria de Ciência e Tecnologia do Estado do Paraná, and the CNPq for the financial support for the present work.

\section{REFERENCES}

Amato, V.S., Tuon, F.F., Bacha, H.A., Amato Neto, V., Nicodemo, A.C. (2008), Mucosal leishmaniasis. Current scenario and prospects for treatment. Acta Trop., 105, 1-9.

Arevalo, J., Inga, R., López, M. (1993), PCR detection of Leishmania braziliensis. In: DH Persing, TF Smith, FC Tenover and TJ White (ed). Diagnostic molecular microbiology: principles and applications. American Society Microbiology. Washington, D.C. pp. 456-461.
Aviles, H., Belli, A., Armijos, R. (1999), PCR detection and identification of Leishmania parasites in clinical specimens in Ecuador: a comparison with classical diagnostic methods. J. Parasitol., 85,181187.

Belli, A., Rodriguez, B., Aviles, H., Harris, E. (1998), Simplified Polymerase Chain Reaction Detection of New World Leishmania in Clinical Specimens of Cutaneous Leishmaniasis. Am. J. Trop. Med. Hyg., 58, 102-109.

Boaventura, V., Oliveira, J.G., Costa, J., Novais, F., de Oliveira, C.I., Barral Neto, M., Barral, A. (2009), The value of the otorhinolaryngological exam in correct ML diagnosis. Am. J. Trop. Med. Hyg., 81, 384-386.

Brasil, (2007), Ministério da Saúde, Secretaria de Vigilância em Saúde. Manual de Vigilância da Leishmaniose Tegumentar Americana. Brasília: Editora Ministério da Saúde, 2a .ed., pp. 1-182.

Bruijn, M.H.L., Barker, C.D. (1992), Diagnosis of New World leishmaniasis: specific detection of the Leishmania braziliensis complex by amplification of kinetoplast DNA. Acta Trop., 52, 45-58.

Bruijn, M.H.L., Labrada, L.A., Smyth, A.J. (1993), A comparative study of diagnosis by the polymerase chain reaction and by current clinical methods using biopsies from Colombian patients with suspected leishmaniasis. Trop. Med. Parasitol., 44, 201-207.

Castro, E.A., Thomaz-Soccol, V., Membrive N., Luz, E. (2002), Estudo das características epidemiológicas e clínicas de 332 casos de leishmaniose tegumentar notificados na região norte do Estado do Paraná de 1993 a 1998, Rev. Soc. Bras. Med. Trop., 35, 445-452.

Castro, E.A., Luz, E., Telles, F.Q., Pandey, A., Biseto, A., Dunaiski, M., Sbalqueiro, I., Thomaz-Soccol, V. (2005), Eco-epidemiological survey of Leishmania (Viannia) braziliensis American cutaneous and mucocutaneous leishmaniasis in Ribeira Valley River, Paraná State, Brazil. Acta Trop., 93, 141-149.

Curti, M.C.M., Silveira, T.G.V., Arraes, S.M.A.A., Bertolini, D.A., Zanzarini, P.D., Venazzi, E.A.S., Fernandes, A.C.S., Teixeira, J.J.V., Lonardoni, M.V.C. (2009), Aspectos epidemiológicos da Leishmaniose Tegumentar Americana na região Noroeste do Estado do Paraná. Rev. Ciênc. Farm Básica Apli., 30, 51-56.

Dedet, J.P. (2009), Leishmanies, leishmanioses: biologie, clinique et thérapeutique. EMC (Elsevier Masson SAS, Paris), Maladies infectieuses, 8, 506-510.

Eresh, S., Mccallum, S.M., Barker, D.C. (1994), Identification and diagnosis of Leishmania mexicana complex isolates by polymerase chain reaction. Parasitol., 109, 423-433.

Gomes, A.H., Armelin, I.M., Menon, S.Z, PereiraChioccola, V.L. (2008), Leishmania (V.) braziliensis: detection by PCR in biopsies from 
patients with cutaneous leishmaniasis. Exp. Parasitol., 119, 319-324.

Guevara, P., Alonso, G., da Silveira, J.F., Mello, M., Scorza, J.V., Anez, N., Ramirez, J.L. (1992), Identification of new world Leishmania using ribosomal gene spacer probes. Mol. Bioch. Parasitol., 56, 15-26.

Lachaud, L., Marchergui-Hammami, S., Chabbert, E. (2002), Comparison of six PCR methods using peripheral blood for detection of canine visceral Leishmaniasis. J. Clin. Microbiol., 40, 210- 215.

Lopes, M., Ingá, R., Cangalaya, M. (1993), Diagnosis of Leishmania using the polymerase chain reaction: a simplified procedure for field work. Am. J. Trop. Med. Hyg., 49,348-356.

Luz, E., Membrive, N., Castro, E.A., Dereure, J., Pratlong, F., Dedet, J.A., Pandey, A., ThomazSoccol, V. (2000), Lutzomyia whitmani (Diptera: Psychodidae) as vector of Leishmania (V.) braziliensis in Paraná state, southern Brazil. Ann. Trop. Med. Parasitol., 4, 623-631.

Mayrink, W., Williams, P., Coelho, M.V., Martins, A.V., Magalhães, P.A., Costa, C.A., Falcão, A.R., Melo, M.N., Falcão, A.L. (1979), Epidemiology of dermal leishmaniasis in the Rio Doce Valley, State of Minas Gerais, Brazil. Ann. Trop. Med. Parasitol., 73, 123-137.

Medeiros, A.C.R., Rodrigues, S.S., Roselino A.M.F.(2002), Comparison of the specificity of PCR and the histopathological detection of Leishmania for the diagnosis of american cutaneous leishmaniasis. Braz. J. Med. Biol. Res., 35,421-424.

Mimori, T., Sasaki, J., Nakata, M., Gomez, E.A., Uezato, H., Nonaka, S., Hashiguchi, Y., Furuya, M., Saya, H. (1998), Rapid identification of Leishmania species from formalin-fixed biopsy samples by polymorphism-specific polymerase chain reaction. Gene, 210, 179-186.

Opas: Organização Panamericana de la Salud. (1994), La Leishmaniosis en las Américas. Boletin Epidemiologico, 15, 1, pp. 8-13.

Pereira, E.F., Thomaz-Soccol, V., Lima, H.C., Thomaz-Soccol, V., Castro, E.A., Mulinari-Brenner, F., Queiroz-Telles, F., Luz, E. (2008), Diagnosis of leishmaniosis in the Paraná state of southern Brazil. Exp. Dermatol., 17, 1200-1212.

Piñero, J., Martinez, E., Pacheco, R., Aragon, Z., Armas, F., Del Castilho, A., Valladares, B. (1999), PCR-ELISA for diagnosis of mucocutaneous leishmaniasis. Acta Trop., 73, 21-29.

Pirmez, C., Silva-Trajano, V., Neto, M.P.O., Cruz, A., Gonçalves-da-Costa, S. C., Catanho, M., Degrave, W., Fernandes, O. (1999), Use of PCR in diagnosis of human American Tegumentary Leishmaniasis in Rio de Janeiro, Brazil. J. Clin. Microbiol., 37, 18191823.
Rodrigues, E.H.G., Brito, M.E.F., Mendonça M.G. (2002), Evaluation of PCR for Diagnosis of American Cutaneous Leishmaniasis in an Area of Endemicity in Northeastern Brazil. J. Clin. Microbiol., 40, 3572-3576.

Rodriguez, N., Bernardo, G., Rodas, A., Howard, T., Jacinto, C. (1994), Diagnosis of Cutaneous Leishmaniais and Species Discrimination of Parasites by PCR and Hybridization. J. Clin. Microbiol., 32, 2246-2252.

SESA - Secretaria de Estado de Saúde do Estado do Paraná (2002), Série histórica de casos de leishmaniose tegumentar no Paraná. 2002, pp. 1- 98.

Silveira, T.G.V., Arraes, S.M.A., Bertolini, D.A., Teodoro, U., Lonardoni, M.V.C., Roberto, A.C.B.S., Ramos, M., Sobrinho, A.N., Ishikawa, E., Shaw, J. (1999), Observações sobre o diagnóstico laboratorial e a epidemiologia da leishmaniose tegumentar no Estado do Paraná. Rev. Soc. Bras. Med. Trop., 32, 413-423

Singh, S., Sivakumar, R. (2003), Recent Advances in the Diagnosis of Leishmaniasis. Postgraduate Med. J., 49, 55-60.

Teodoro, U., Thomaz Soccol, V., Kühl, J.B.,Santos, D., Santos, E., Santos, A., Abbas, M., Dias, A.C. (2004), Reorganization and cleanness of peridomiciliar area to control sand flies (Diptera, Psychodidae, Phlebotominae) in South Brazil. Braz. Arch. Biol. Technol., 47, 205-212.

Thomaz-Soccol, V., Castro, E.A., Carvalho, Y., Pereira, E.A., Szargiki, R., Alcântara, F., Machado, A.M., Wolodymir K.W., Luz E., (2009), A new focus of cutaneous leishmaniasis in the central area of the State of Paraná, south of Brazil. Acta Trop., 111, 308-315

Thomaz-Soccol, V., Castro, E.A., Luz, E., Dereure, J., Pratlong, F., Membrive, N., Dedet, J.P. (2003), Leishmania species in two regions of Paraná, Brazil: biochemical characterization by isoenzyme electrophoresis. In: Roussos S., Soccol C.R., Pandey A., Augur C., eds. New Horizons in Biotechnology. Dordrecht: Kluwer Academic Publishers, pp. 429439.

Weigle, K.A., Labrada, L.A., Lozano, C. (2002), PCR based diagnosis of acute and chronic cutaneous Leishmaniasis caused by Leishmania (Viannia). J. Clin. Microbiol., 40, 601-606.

Who: World Health Organization (2006), Leishmaniasis. Available from; http://www.who.int/ leishmaniasis.
Received: February 03, 2010; Revised: November 03, 2010; Accepted: March 15, 2011. 